\title{
Stator winding fault detection of induction generator based wind turbine using ANN
}

\author{
N. F. Fadzail, S. Mat Zali, M. A. Khairudin, N. H. Hanafi \\ School of Electrical System Engineering Universiti Malaysia Perlis, Malaysia
}

\begin{tabular}{l} 
Article Info \\
\hline Article history: \\
Received Nov 4, 2019 \\
Revised Dec 23, 2019 \\
Accepted Jan 20, 2020 \\
\hline
\end{tabular}

\section{Keywords:}

Artificial neural network

Fault detection

Induction generator

Wind turbine

\begin{abstract}
This paper presents a stator winding faults detection in induction generator based wind turbines by using artificial neural network (ANN). Stator winding faults of induction generators are the most common fault found in wind turbines. This fault may lead to wind turbine failure. Therefore, fault detection in induction generator based wind turbines is vital to increase the reliability of wind turbines. In this project, the mathematical model of induction generator based wind turbine was developed in MATLAB Simulink. The value of impedance in the induction generators was changed to simulate the inter-turn short circuit and open circuit faults. The simulated responses of the induction generators were used as inputs in the ANN model for fault detection procedures. A set of data was taken under different conditions, i.e. normal condition, inter-turn short circuit and open circuit faults as inputs for the ANN model. The target outputs of the ANN model were set as ' 0 ' or ' 1 ', based on the fault conditions. Results obtained showed that the ANN model can detect different types of faults based on the output values of the ANN model. In conclusion, the stator winding faults detection procedure for induction generator based wind turbines by using ANN was successfully developed.
\end{abstract}

Copyright (C) 2020 Institute of Advanced Engineering and Science. All rights reserved.

\section{Corresponding Author:}

Noor Fazliana Fadzail,

School of Electrical System Engineering,

Universiti Malaysia Perlis,

Pauh Putra Campus 02600 Arau, Perlis, Malaysia.

Email: fazlianafadzail@unimap.edu.my

\section{INTRODUCTION}

Wind Turbines have become one of the important topics and treated as a future technology because it's clean, free, reliable and it efficiency [1]. It is also become a major supplier of consumer electricity. With an increasing number of wind turbines in use, monitoring the condition of wind turbine becomes an important aid for maintenance and improved reliability [2-7]. Based on a report from Germany, 23.5\% of wind turbines turbine breakdowns in 2009 was due to generator failures [8]. Out of this percentage, bearing related faults are most common leading with $40 \%$; followed by stator related faults, $38 \%$ and rotor related faults, $10 \%$ [9]. This showed that stator winding fault is one of the major faults occurring in wind turbine generators. Stator winding faults are related to failure involving stator winding short circuit and open circuit [10-11]. Inter-turn short circuit fault is the most common stator winding faults. It is very serious as it may cause a rapid rise in temperature near the short circuit turns, which may further result in the destruction of the insulation for the turns, which leads to coil and winding short circuits and even catastrophic machine failures [12].

Previously, there were few researches on fault detection for wind turbines. In [13-14], fault detection of wind turbine using SCADA data were presented. Artificial neural network was used in [15] for fault detection of wind turbine via current signature analysis. A method for sensor validation and fault detection in wind turbine by using ANN was proposed in [16]. Fault detection of wind energy conversion system based on 
dynamic neural network was developed in [17]. The presented fault detection system detects faults in the generator's angular velocity sensors, pitch angle sensors, and pitch actuators. In [18], an imbalance fault detection algorithm for variable-speed wind turbines using neural network was proposed. This paper focuses on wind turbine blade imbalance faults. A fault detection of incipient faults of short-circuits in induction generators was designed in [19] using machine learning. Meanwhile, in [20] wound rotor induction generator inter-turn short circuit diagnosis using a new digital neural network was presented.

Many previous studies proposed a method of fault detection for wind turbines form SCADA data. Some of these research were not focused on generator faults in wind turbines. Therefore, this limits the capability of a fault detection method when a fault occurs in the generator, especially for inter-turn short circuit and open circuit stator windings. Artificial neural network is a common method used in fault detection due to its capability to detect different types of faults [21]. An artificial neural network could be applied to a wide range of tasks like signal processing, pattern recognition, function approximation, and classification [22]. An artificial neural network is the computation of biological neurons connected by weights that are modified during use to satisfy the performance criterion [23-24]. Neural networks are qualified as a universal approximators, they can mimic every complex function [25].

This paper presents, the mathematical model of an induction generator based wind turbine was developed in MATLAB Simulink. As stated in $[9,26]$, the fault condition would change the impedance of the winding, affecting the resistance and the winding inductance would change as well. Therefore, in this project, the value of impedance of the induction generator was changed to simulate the inter-turn short circuit and open circuit faults. The impedance of the induction generator was changed by 0.1 times the normal value to simulate the inter-turn fault [27]. Inter-turn short circuit fault was considered to have only a small resistance. Therefore, its resistance could be assumed zero $[12,28]$. Meanwhile, the inductance of the induction generator was changed by 10 times the normal value to simulate the open circuit fault [28]. The simulation results of the induction generator were used as inputs in the ANN model for fault detection. There were four inputs; which were stator current, electrical torque, mechanical torque and rotor speed. A set of data was taken under different conditions, i.e. normal condition, inter-turn short circuit and open circuit faults, as inputs for the ANN model for training proses. The target outputs of the ANN model were set as ' 0 ' or ' 1 ', based on the fault condition. After the training process was successful, the ANN model was tested and validated with different values of input under different conditions.

\section{FAULT DETECTION METHOD}

\subsection{Faulty condition}

Wind generation with induction generator was developed in MATLAB Simulink. The wind turbine model included three main components which were aerodynamics, drivetrain and generator. The model was simulated under normal condition with parameter value of stator phase resistance, $R_{S}=0.425 \Omega$, inductance on d-axis, $L d=0.0082 \mathrm{H}$ and inductance on q-axis, $L_{q}=0.0082 \mathrm{H}$.

In simulating the fault conditions, the parameter values $R_{s}, L d$ and $L_{q}$ were changed to $R_{s}=0.0425 \Omega$, $L d=0.00082 \mathrm{H}$ and $L_{q}=0.00082 \mathrm{H}$ which were 0.1 times the normal value to produce the inter-turn short circuit fault. Then, the parameter values $R s, L_{d}$ and $L_{q}$ were changed to $R s=4.25 \Omega, L d=0.082 \mathrm{H}$ and $L_{q}=0.082 \mathrm{H}$ which were 10 times the normal value to replicate the open circuit fault. Later, the responses of stator current, $I s$, rotor speed, $W_{m}$, electrical torque, $T_{e}$ and mechanical torque, $T_{m}$ were measured. These simulated responses were used to develop the ANN model for fault detection and classification procedures.

\subsection{Artificial neural network}

The fault detection procedure is shown in Figure 1. All the simulated responses $\left(I_{s}, T_{e}, T_{m}\right.$ and $\left.W_{m}\right)$ were used to develop the ANN model for fault detection. The target output of ANN model were set as shown in Figure 1. Basically, neural networks are trained until the output follow the target output. Figure 2 shows the adjustment of ANN training process. The ANN will be trained with the inputs by adjusting the weight until the output matches the target output.

Figure 3 represents the structure of the neural network used in MATLAB for the training process. The ANN model for fault detection was developed with four inputs and three outputs. The inputs of ANN model were stator current, $I s$, electrical torque, $T_{e}$, mechanical torque, $T_{m}$ and rotor speed, $W_{m}$. Moreover, the outputs of ANN model were $\mathrm{X}, \mathrm{Y}$ and $\mathrm{Z}$. The outputs of $\mathrm{X}, \mathrm{Y}$ and $\mathrm{Z}$ were set as ' 0 ' and ' 1 ' based on fault conditions. Table 1 shows the target output of the ANN model. It consists of three conditions which are normal, inter-turn short circuit fault and open circuit fault. 


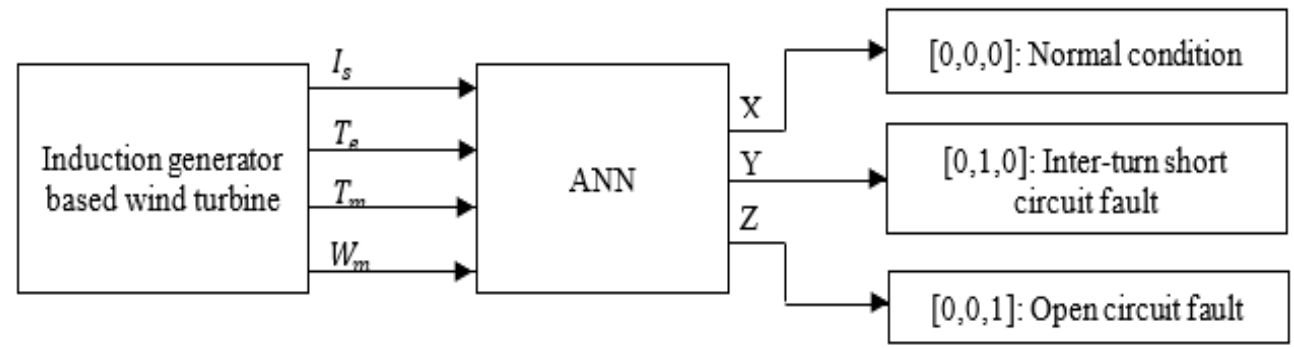

Figure 1. Fault detection and classification procedure

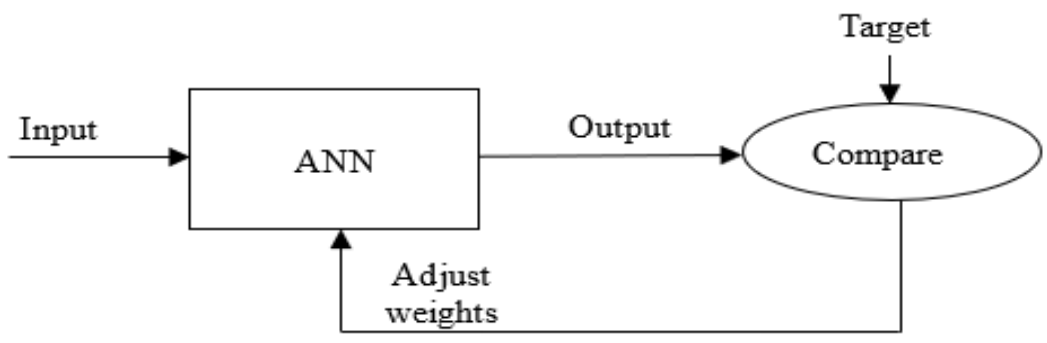

Figure 2. Adjustment of the ANN training process

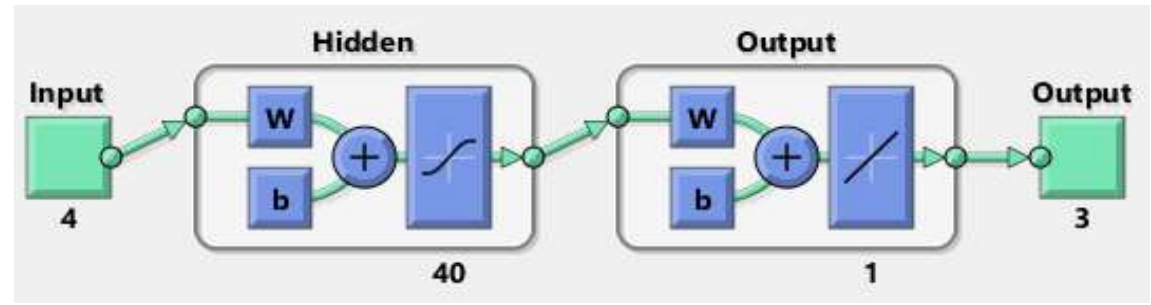

Figure 3. Structure of neural network

Table 1. The Target output of ANN model

\begin{tabular}{lccc}
\hline Condition & $\mathrm{X}$ & $\mathrm{Y}$ & $\mathrm{Z}$ \\
\hline Normal & 0 & 0 & 0 \\
Inter-turn short circuit fault & 0 & 1 & 0 \\
Open circuit fault & 0 & 0 & 1 \\
\hline
\end{tabular}

\section{RESULTS AND DISCUSSIONS}

A fault occurred at 7 second in the simulation. There are two types of fault responses which are inter-turn short circuit and open circuit faults. Figure 4 shows the simulated responses for stator current, Is under normal condition with inter-turn short circuit fault occurring at 7 second while Figure 5 shows the response of stator current, Is under normal condition with open circuit fault at 7 second. Based on the figures, the inter-turn fault current led to high peak fault current and the stator current dropped during the open circuit fault. The inter-turn short circuit current caused an instantaneous shock to the current as shown in Figure 4.

Figure 6 shows the responses for rotor speed, $W m$ under normal condition with inter-turn short circuit fault at 7 second. Figure 7 shows the responses for rotor speed, $W m$ for normal condition with open circuit fault at 7 second. Noticeable, the rotor speed of induction generator decreased during inter-turn short circuit fault and increased during open circuit fault.

The simulated responses for electrical torque, $T e$ under normal condition during inter-turn short circuit fault at 7 second is shown in Figure 8. Additionally, the simulated responses for electrical torque, Te under normal condition with open circuit fault at 7 second is shown in Figure 9. The inter-turn short circuit fault caused the electrical torque to increase whereas the open circuit fault decreased the electrical torque. 


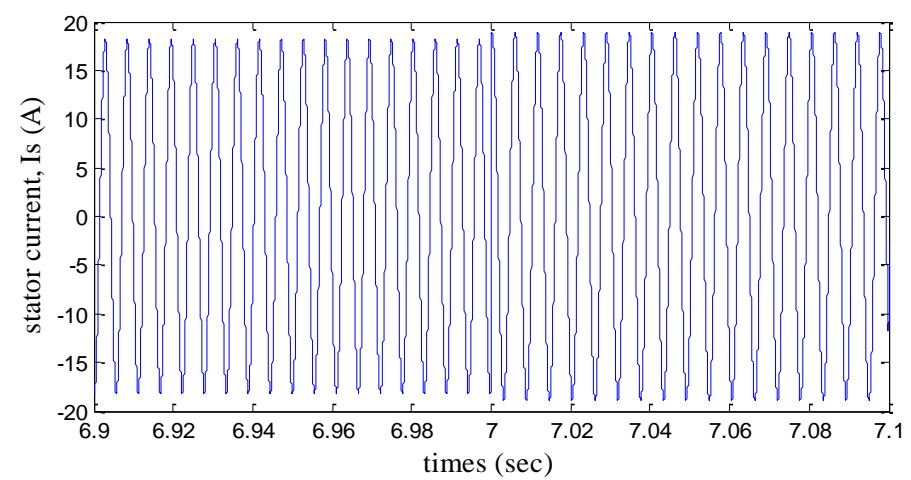

Figure 4. Simulated response of stator current, $I_{s}$ under normal condition with inter-turn short circuit fault at 7 second

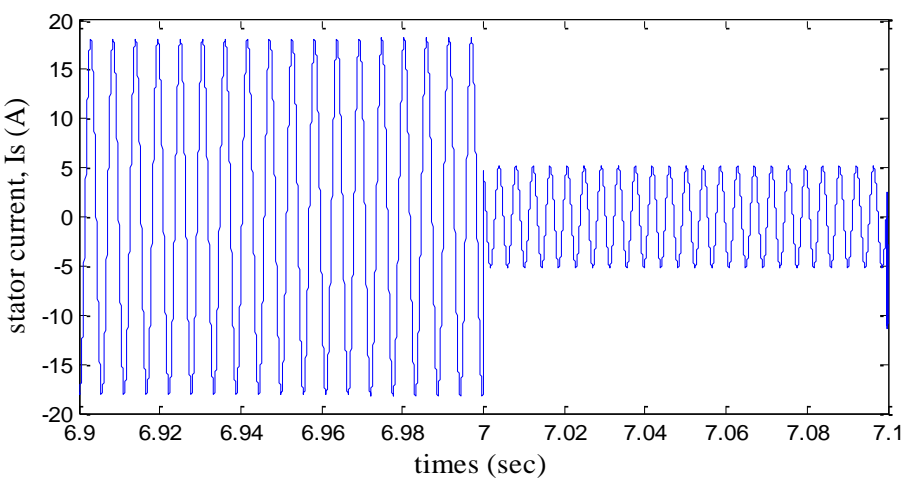

Figure 5. Simulated response of stator current, $I_{s}$ under normal condition with open circuit fault at 7 second

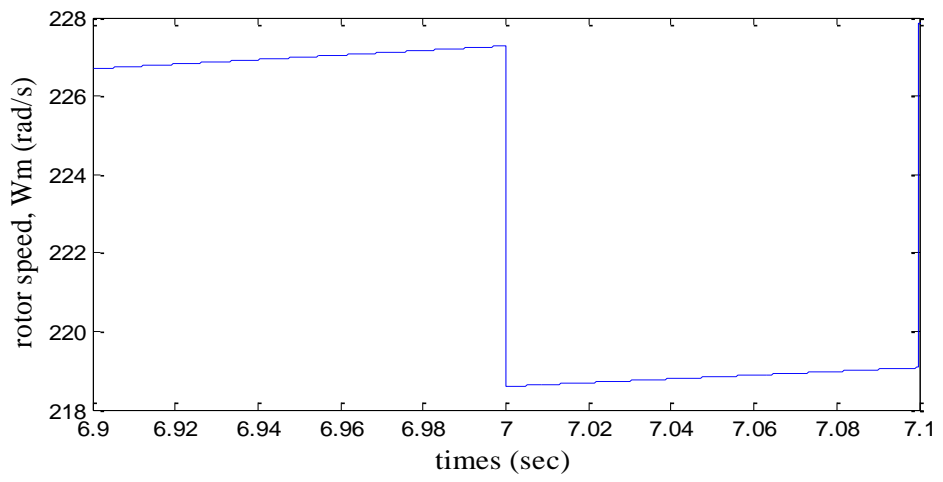

Figure 6. Simulated response of rotor speed, $W_{m}$ under normal condition with inter-turn short circuit fault at 7 second

The simulated responses for mechanical torque, Tm under normal condition during inter-turn short circuit fault at 7 second is shown in Figure 10 while Figure 11 presents the simulated responses for mechanical torque, $T m$ under normal condition with open circuit fault at 7 second. The simulated responses showed that when inter-turn short circuit fault happened, the responses for mechanical torque, Tm reduced. Meanwhile, the responses for mechanical torque, $\mathrm{Tm}$ increased as open circuit fault occurred.

After the training process was satisfactory, the ANN model for fault detection was tested. The ANN model was tested and validated with different input values. Table 2 shows the results of the test and validation of the ANN model under different conditions. The results showed that the output of ANN model tallied with the target output. 


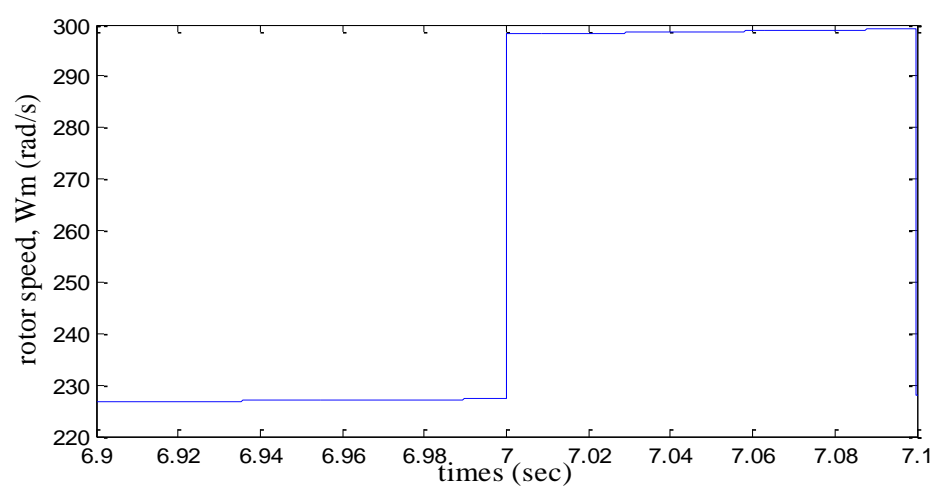

Figure 7. Simulated response of rotor speed, $W_{m}$ under normal condition with open circuit fault at 7 second

Figure 12 and Figure 13 present the classification results under different fault conditions. The output value in Figure 12 clearly shown that the target output is $[0 ; 1 ; 0]$. This indicated that the induction generator based wind turbine experienced an inter-turn short circuit fault. Meanwhile, the output vector in Figure 13 is $[0 ; 0 ; 1]$ which indicated that an open circuit fault occurred.

Based on the result of the ANN model for fault classification, it can be observed that the ANN model can detect accurately the different types of faults based on stator current, $I S$, electrical torque, $T e$, mechanical torque, $\mathrm{Tm}$ and rotor speed, $\mathrm{Wm}$. The accuracy of the fault detection procedure confirmed the effectiveness of the stator winding fault detection in induction generator based wind turbines.

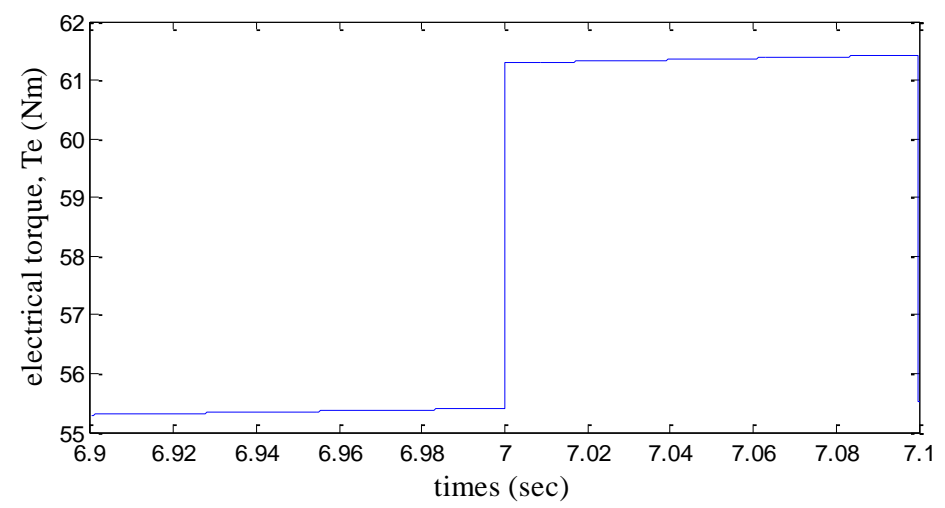

Figure 8. Simulated response of electrical torque, $T_{e}$ under normal condition with inter-turn short circuit fault at 7 second

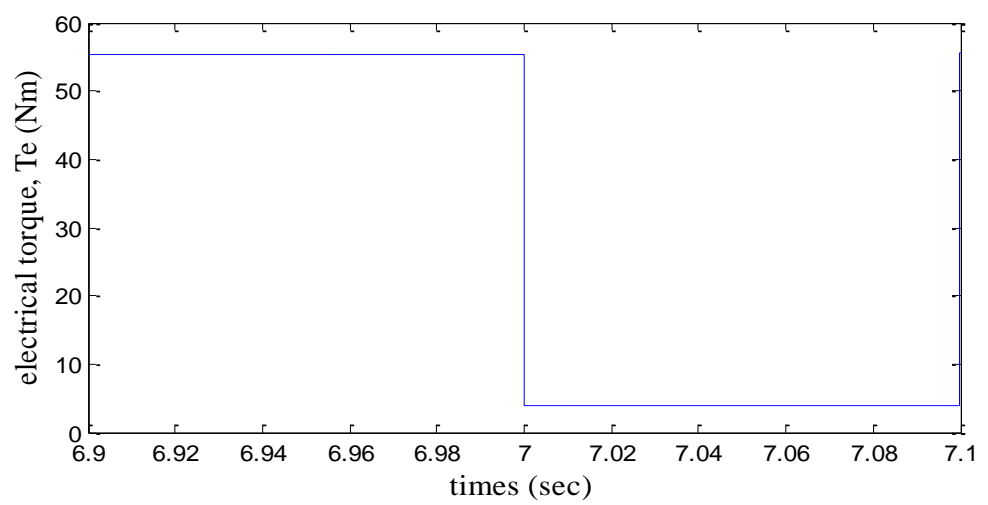

Figure 9. Simulated response of electrical torque, $T_{e}$ under normal condition with open circuit fault at 7 second 


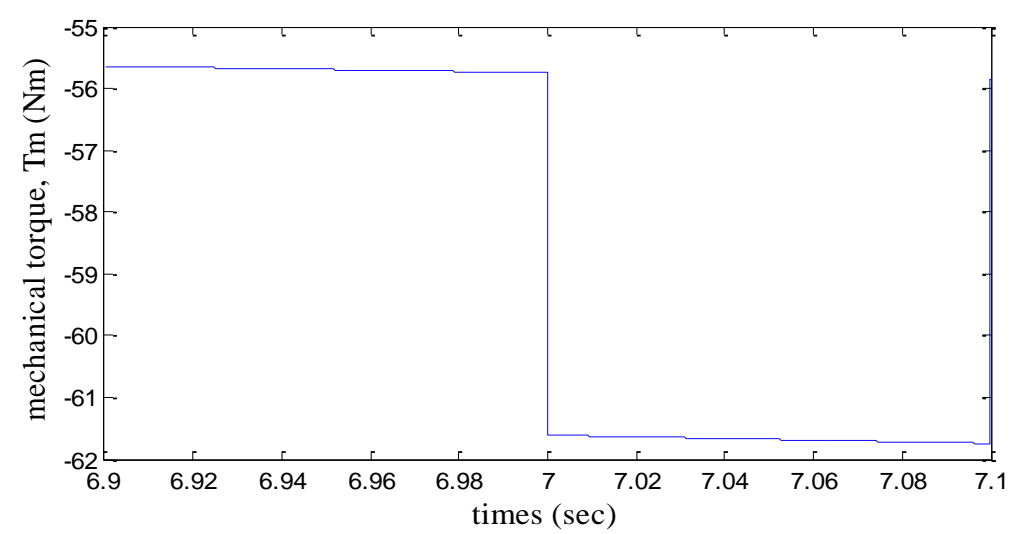

Figure 10. Simulated response of mechanical torque, $T_{m}$ for normal condition with inter-turn short circuit fault at 7 second

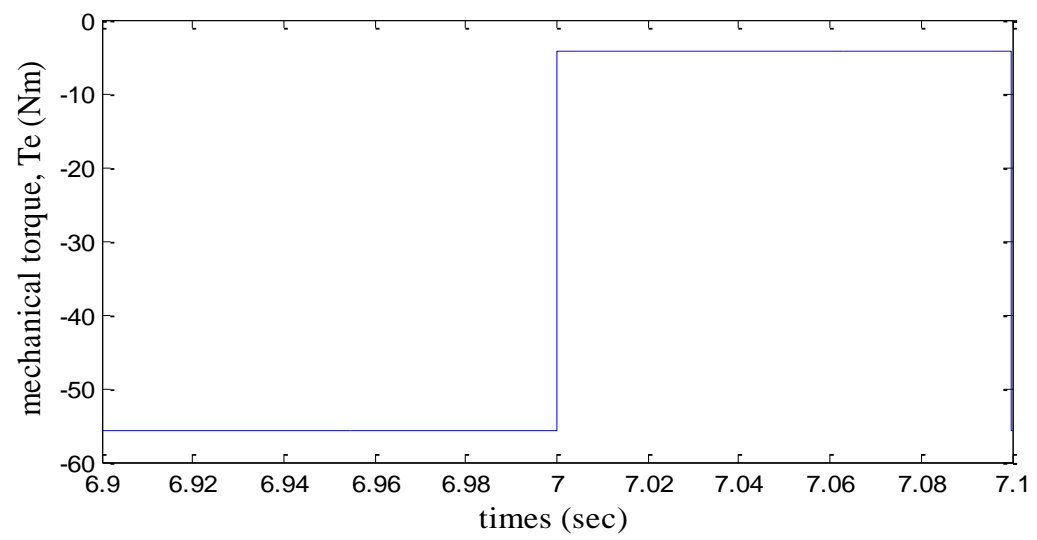

Figure 11. Simulated response of mechanical torque, $T_{m}$ for normal condition with open circuit at 7 second

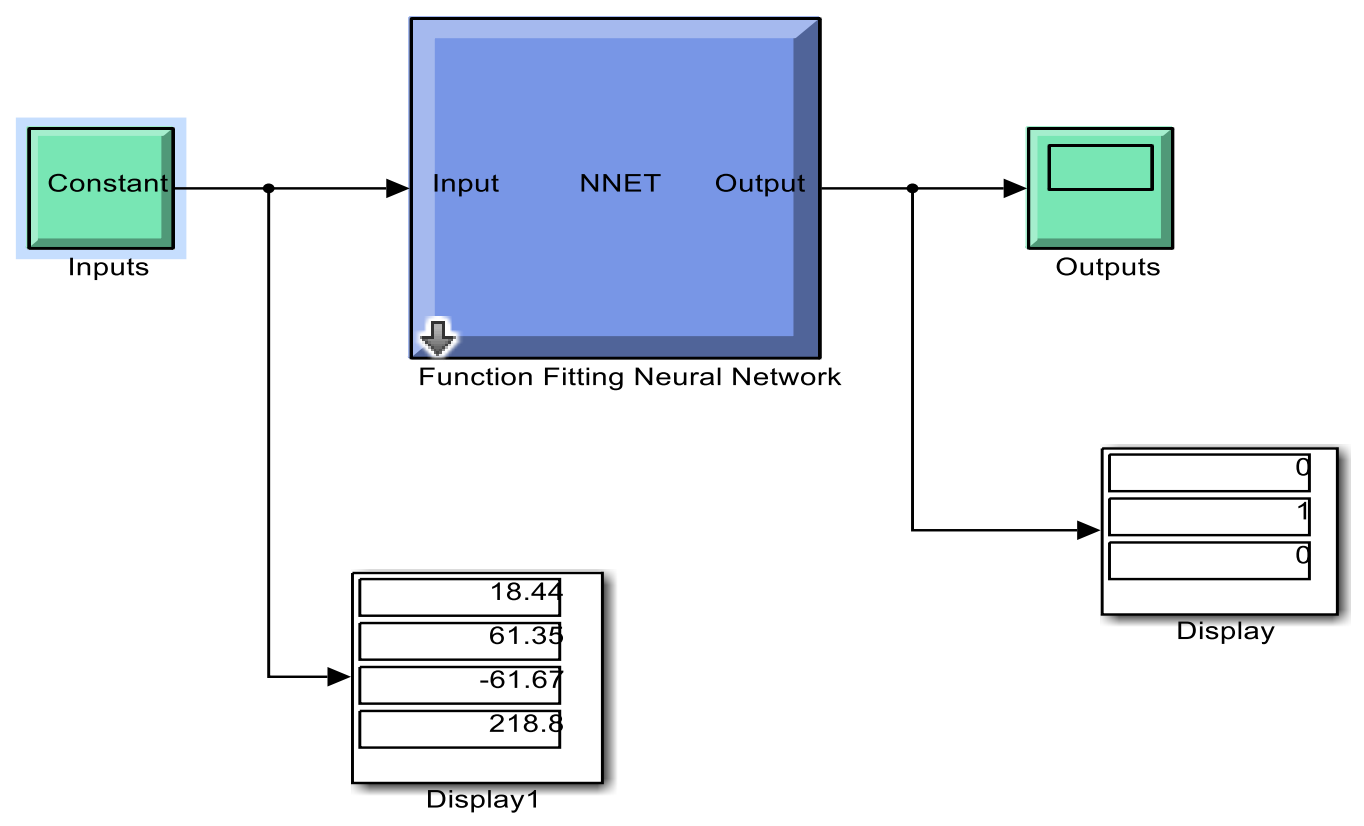

Figure 12. Result for inter-turn short circuit fault detection 


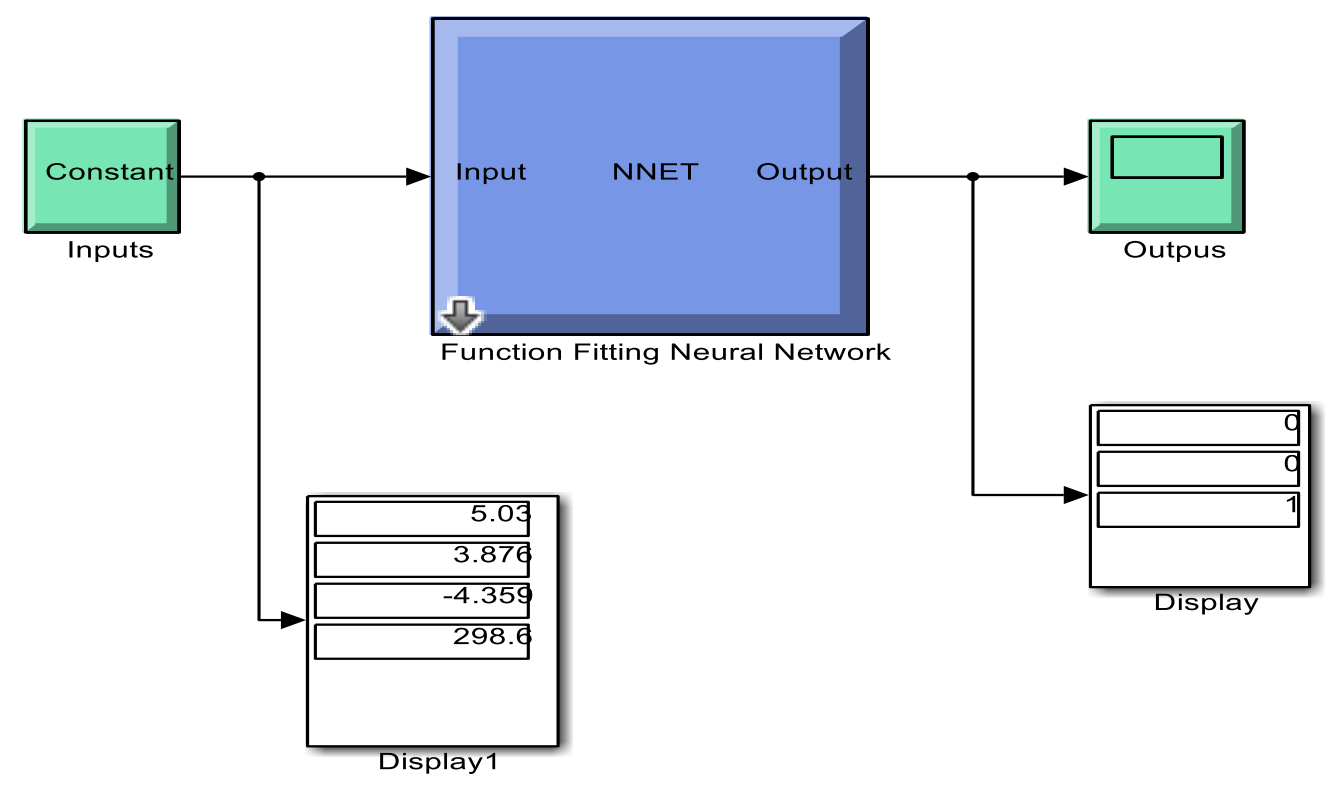

Figure 13. Result for open circuit fault detection

Table 2. The Result of test and validation of ANN Model

\begin{tabular}{ccccccccccc}
\hline \multirow{2}{*}{ Test } & \multicolumn{3}{c}{ Inputs } & \multicolumn{4}{c}{ Targets } & \multicolumn{3}{c}{ Outputs } \\
& Is (A) & Te $(\mathrm{Nm})$ & $\mathrm{Tm}(\mathrm{Nm})$ & $\mathrm{Wm}(\mathrm{rad} / \mathrm{sec})$ & $\mathrm{X}$ & $\mathrm{Y}$ & $\mathrm{Z}$ & $\mathrm{X}$ & $\mathrm{Y}$ & $\mathrm{Z}$ \\
\hline 1 & -17.9562 & 55.2968 & -55.6379 & 226.6926 & 0 & 0 & 0 & 0 & $-7.6 \mathrm{E}-6$ & 0 \\
2 & 6.2662 & 61.3911 & -61.7099 & 218.9492 & 0 & 1 & 0 & 0 & 1 & 0 \\
3 & 4.6859 & 3.8717 & -4.3542 & 298.9699 & 0 & 0 & 1 & 0 & 0 & 1 \\
4 & 16.8312 & 55.3660 & -55.7066 & 227.0641 & 0 & 0 & 0 & 0 & 0 & $1.2 \mathrm{E}-5$ \\
5 & 3.9135 & 3.8749 & -4.3577 & 298.6992 & 0 & 0 & 1 & 0 & 0 & 1 \\
\hline
\end{tabular}

\section{CONCLUSION}

In conclusion, the developed ANN model was proven to be a less complicated method to detect different types of faults as it was developed by data training from simulated responses of wind turbines. Moreover, the developed ANN model for fault detection had shown good efficiency, based on the output and target values of the ANN fault classifier model, which were exactly the same. Therefore, the stator winding fault detection and classification procedure for induction generator based wind turbine by using ANN was successfully developed.

\section{ACKNOWLEDGEMENTS}

The author would like to acknowledge the support from the Fundamental Research Grant Scheme (FRGS) under a grant number of FRGS/1/2017/TK10/UNIMAP/02/10 from the Ministry of Education Malaysia.

\section{REFERENCES}

[1] A. A. Bensaber, M. Benghanem, M. A. Bensaber, and A. Guerouad, "Nonlinear Adaptive Control for Wind Turbine Under Wind Speed Variation," IAES Int. J. Robot. Autom., vol. 7, no. 2, p. 89, 2018.

[2] S. Djurovic, S. Williamson, P. J. Tavner, and W. Yang, "Condition monitoring artefacts for detecting winding faults in wind turbine DFIGs," in European Wind Energy Conference and Exhibition 2009, EWEC 2009, 2009, vol. 1, pp. 491-512.

[3] P. Tchakoua, R. Wamkeue, M. Ouhrouche, F. Slaoui-Hasnaoui, T. A. Tameghe, and G. Ekemb, "Wind turbine condition monitoring: State-of-the-art review, new trends, and future challenges," Energies, vol. 7, no. 4. pp. 2595-2630, 2014.

[4] "Prognostic condition monitoring for wind turbine drivetrains via generator current analysis," Chinese J. Electr. Eng., vol. 4, no. 3, pp. 80-89, 2019. 
[5] Pezzani, C. M., Bossio, J. M., Castellino, A. M., Bossio, G. R., \& De Angelo, C. H., "A PLL-based resampling technique for vibration analysis in variable-speed wind turbines with PMSG: A bearing fault case" Mechanical Systems and Signal Processing, 85, 354-366, 2017.

[6] P. Guo, D. Infield, and X. Yang, "Wind turbine generator condition-monitoring using temperature trend analysis," IEEE Trans. Sustain. Energy, vol. 3, no. 1, pp. 124-133, 2012.

[7] L. M. Popa, B. B. Jensen, E. Ritchie, and I. Boldea, "Condition Monitoring of Wind Generators," in Conference Record - IAS Annual Meeting (IEEE Industry Applications Society), 2003, vol. 3, pp. 1839-1846.

[8] M. B. Abadi, S. M. A. Cruz, A. P. Gonçalves, A. M. S. Mendes, A. Ribeiro, and F. Silva, "Inter-turn fault detection in doubly-fed induction generators for wind turbine applications using the stator reactive power analysis," in IET Conference Publications, 2014, vol. 2014, no. CP651.

[9] S. Martens, N. Mijatovic, J. Holbøll, G. A. Skrimpas, and C. W. Sweeney, "Simulation of Electric Faults in DoublyFed Induction Generators Employing Advanced Mathematical Modelling," Proc. Nord. Insul. Symp., no. $24,2017$.

[10] F. Cira, M. Arkan, and B. Gumus, "Detection of stator winding inter-turn short circuit faults in permanent magnet synchronous motors and automatic classification of fault severity via a pattern recognition system," J. Electr. Eng. Technol., vol. 11, no. 2, pp. 416-424, 2016.

[11] Wenxian Yang, P. J. Tavner, and M. Wilkinson, "Wind Turbine Condition Monitoring and Fault Diagnosis Using Both Mechanical and Electrical Signatures," 2008, pp. 1296-1301.

[12] C. Wang, X. Liu, and Z. Chen, "Incipient stator insulation fault detection of permanent magnet synchronous wind generators based on hilbert-huang transformation," IEEE Trans. Magn., vol. 50, no. 11, 2014.

[13] Y. Zhao, D. Li, A. Dong, D. Kang, Q. Lv, and L. Shang, "Fault prediction and diagnosis of wind turbine generators using SCADA data," Energies, vol. 10, no. 8, 2017.

[14] A. Lebranchu, S. Charbonnier, C. Berenguer, and F. Prevost, "Using SCADA data for fault detection in wind turbines: Local internal model versus distance to a wind farm reference," in Applied Condition Monitoring, vol. 4, 2016, pp. $225-236$.

[15] R. K. Ibrahim, J. Tautz-Weinert, and S. J. Watson, "Neural networks for wind turbine fault detection via current signature analysis," Present. Wind Eur. Summit 2016, 2016.

[16] A. G. Kavaz and B. Barutcu, "Fault detection of wind turbine sensors using artificial neural networks," J. Sensors, vol. 2018, 2018.

[17] N. Talebi, M. A. Sadrnia, and A. Darabi, "Robust fault detection of wind energy conversion systems based on dynamic neural networks," Comput. Intell. Neurosci., vol. 2014, 2014.

[18] J. Chen et al., "An Imbalance Fault Detection Algorithm for Variable-Speed Wind Turbines: A Deep Learning Approach," Energies, vol. 12, no. 14, p. 2764, 2019.

[19] P. P. Rebouças Filho, N. M. M. Nascimento, I. R. Sousa, C. M. S. Medeiros, and V. H. C. de Albuquerque, "A reliable approach for detection of incipient faults of short-circuits in induction generators using machine learning," Comput. Electr. Eng., vol. 71, pp. 440-451, 2018.

[20] S. Toma, L. Capocchi, and G. A. Capolino, "Wound-rotor induction generator inter-turn short-circuits diagnosis using a new digital neural network," IEEE Trans. Ind. Electron., vol. 60, no. 9, pp. 4043-4052, 2013.

[21] S. Heo and J. H. Lee, "Fault detection and classification using artificial neural networks," IFAC-PapersOnLine, vol. 51, no. 18, pp. 470-475, 2018.

[22] Hussain K. Khleaf, Ali K. Nahar and Ansam S. Jabbar, "Intelligent control of DC-DC converter based on PID-neural network," International Journal of Power Electronics and Drive System, vol. 10, no. 4, p. 2254-2262, 2019.

[23] N. Model, S. Neuron, T. Functions, M. Neuron, N. Architectures, and R. Networks, "Neuron Model and Network Architectures," Hagan.okstate.edu, pp. 1-24, 2014.

[24] M. Ruzek, "ARTIFICIAL NEURAL NETWORK FOR MODELS OF HUMAN OPERATOR,” Acta Polytech. CTU Proc., vol. 12, p. 99, 2017.

[25] S. Della Krachai, A. Boudghene Stambouli, M. Della Krachai and M. Bekhti, "Experimental investigation of artifial intelligence applied in MPPT techniques," International Journal of Power Electronics and Drive System, vol. 10, no. 4, p. 2138-2147, 2019.

[26] Y. Liu, R. Qu, J. Wang, H. Fang, X. Zhang, and H. Chen, "Influences of Generator Parameters on Fault Current and Torque in a Large-Scale Superconducting Wind Generator," IEEE Trans. Appl. Supercond., vol. 25, no. 6, 2015.

[27] W. Yang, P. J. Tavner, and R. Court, "An online technique for condition monitoring the induction generators used in wind and marine turbines," Mech. Syst. Signal Process., vol. 38, no. 1, pp. 103-112, 2013.

[28] H. Zhao, W. Hao, H. Wu, Z. Yang, and X. Shi, "Modeling and simulation of aircraft main generator stator winding faults,” J. Comput. Methods Sci. Eng., vol. 17, no. 4, pp. 691-704, 2017. 